\title{
Comparison of Working Postures among Students in School Workshop: A CAD Environment analysis
}

\author{
Adila Md Hashim, Siti Zawiah Md Dawal \\ Engineering design and Manufacture department, Faculty of Engineering, \\ University of Malaya, Malaysia \\ adilamdhashim@yahoo.com.my, sitizawiahmd@um.edu.my
}

Keywords: School workshop; CATIA; RULA; workstation; gender

\begin{abstract}
School furniture was known to be among main contributor of students' back pain and bad postures. However, most studies focused only on the furniture in classroom compared to other facilities in school. Therefore, this study took the initiative to assess students' working postures in school workshop. The objective of this study was to evaluate postural stress of students using RULA method in CATIA. Actual working process was recorded and tasks performed were translated into human model for ergonomic analysis. This evaluation was done in CAD environment via Human Activity Analysis. Result showed the male students have a higher average RULA score compared to the female students. This study discovered that the current workstation was unsuitable for both genders. Both genders have an average scores of more than 5, which indicated changes are required soon. This paper also presented a recommended design of a workstation to reduce musculoskeletal disorder (MSD) symptom and contribute to total back pain prevention for growing adolescents.
\end{abstract}

\section{Introduction}

Many researchers studied a variety of ergonomic risk factors that can lead to back pain and muscle strain among schoolchildren and adolescent. Murphy et al. revealed that characteristics of school furniture have the highest prevalence of relationship with pain [10]. It is agreed by many researchers that school furniture was among several factors that may contribute to musculoskeletal pain (MP) in schoolchildren. Furniture with fixed dimension is more likely not to match with majority of students. Mostly, improper combination of chair and desk dimensions is the reason for discomfort. Pain and musculoskeletal disorder symptoms among schoolchildren is a particularly increasing interest in ergonomic field. It is important to understand the symptoms of lower back pain in children and design early interventions to reduce chronic symptoms when they are adults.

Secondary school students spend at least five hours in school and their activities circulated in classrooms, laboratories, workshops, and sports lesson as part of their learning process. School furniture give a high impact on their posture habit. Their interactions with furniture in these places were proven among the risk factors contributing musculoskeletal disorder and back pain symptoms $[2,3,8]$. Bad postures are associated with feeling of dicomfort while doing activities. Pain usually related with static posture, sitting arrangement and loads carried. Students tend to show variation of posture while seated and performing tasks regardless of the furniture [6]. Different postures may contribute to different sites of discomfort. On the other hand, they are prone to adopt flexed postures when working at the desk. The above results are due to the mismatch problems of school furniture to students' body dimensions. They can develop musculoskeletal disorder and back pain problems if mismatch occurred.[2,9]. With intention to identify ergonomic risk factors among schoolchildren, this paper takes the initiative to evaluate the workstation of Integrated Living Skill's workshop for secondary schools in Malaysia. The aim of this paper is to compare postural scores among students of different genders in the school workshop. Also, the recommended workstation would be able to promote the correct working posture which will reduce the MSD symptom. 


\section{Digital Human Modeling}

Modern methods for ergonomic analysis have rapidly improved since the last decade. More assessment software and computer-based simulation have been introduced in the market to allow researchers to choose the best product to meet their analysis requirements. In designing process of workstations such as assembly task, several Computer Aided Design (CAD) prototypes need to be built for verification of human related factors. In complex manual tasks, the human involvement is very critical as it influences the feasibility, cycle time, work comfort and safety of an operation. The use of these techniques provide a fast and flexible way of creating realistic virtual representations of complete assembly workspaces [1]. It was done by integrating the human presence and intervention in the form of digital mannequins as well as supporting the optimization of the human-productprocess relationship. These techniques have been explored during the last few years for industrial processes verification [12]. Digital prototypes nowadays are significantly useful not only in big industry, but also in small to medium industry. Thus, they play a more important role in product and work layout development. Digital prototypes are able to perform tests of man-machine interaction by using simulation techniques. Moreover, they can identify critical aspects of design and evaluate human motions while dealing with machines or workstations [5]. It is important to perform ergonomic simulation to evaluate man-machine interaction to a new prototype design. This technique is the fastest and cheapest rather than a built prototype which affects time and labor cost.

One of these software products used in this paper is the Computer Aided Tri-Dimensional Interface Application (CATIA) V5. CATIA is a Computer Aided Design (CAD) product by Dassault Systemes. It is equipped with ergonomic tools for human-machine interaction which are Human Builder (HBR), Human Measurement Editor (HME), Human Posture Analysis (HPA) and Human Activity Analysis (HAA). However, ergonomic analysis in CATIA can only be used for static analysis [4].

The advantages of using CATIA ergonomic analysis are the anthropometry data available is extended to Asian population such as Korean and Japanese. It also allow the users to insert their own anthropometric measurement. Moreover, several assessment tools are provided in HAA such as Rapid Upper Limb Analysis (RULA), carry and biomechanics single action analysis.

Using RULA assessment on digital human can give similar results as real human evaluation. RULA assessment is used to analyze the upper section of the body. A RULA sheet consists of body posture diagrams and scoring tables. Based on the RULA method, the human body is divided into two parts, which are part A for Arm and Wrist analysis, while part B for Neck, Trunk and Leg Analysis. A scoring system is used to assign scores at every step, depending on the body position, pointing to higher scores for more awkward postures.

RULA assessment can be classified into 4 action levels. Table 1 shows the RULA indication.

Table 1. RULA indication

\begin{tabular}{ccl}
\hline $\begin{array}{c}\text { Action } \\
\text { level }\end{array}$ & Score & \multicolumn{1}{c}{ Indication } \\
\hline 1 & $1-2$ & Posture is acceptable. \\
2 & $3-4$ & Investigation is needed and changes may be required. \\
3 & $5-6$ & Investigation and changes are required soon. \\
4 & $7<$ & Investigation and changes are required immediately. \\
\hline
\end{tabular}

Some results from RULA assessment are:

- To determine whether the human models can fit themselves to the current workstation.

- To examine postural stress that might develop neck and back pain.

CAD based human modeling software finds effective solution for time and cost saving analysis. This software provide the users to generate three dimensional (3D) human models to interact with their working environment [7]. It is also a well- known method during design development process. This method is preferred because it is cost and time saving. Furthermore, it is validated and able to obtain desirable results. 


\section{Methodology}

In this section, the study performed the posture analysis to compare the scores between male and female subjects. After that, the posture analysis was recalculated for posture intervention. The intervention was an ergonomically designed workstation for school workshop. The proposed workstation was designed based on the anthropometric data collection of 146 Malay students (66 boys, 80 girls) from a school in Klang district, Selangor with the mean age of 14.2 year old. The current and proposed workstations were developed in CAD model.

Figure 1 showed the current workstation for the school workshop. Each workstation was shared by 3 to 4 students at a time. The height, width and depth of the workbench were $78 \mathrm{~cm}, 143 \mathrm{~cm}$ and $84 \mathrm{~cm}$, respectively. The height and diameter of the stool were $58 \mathrm{~cm}$ and $30 \mathrm{~cm}$.

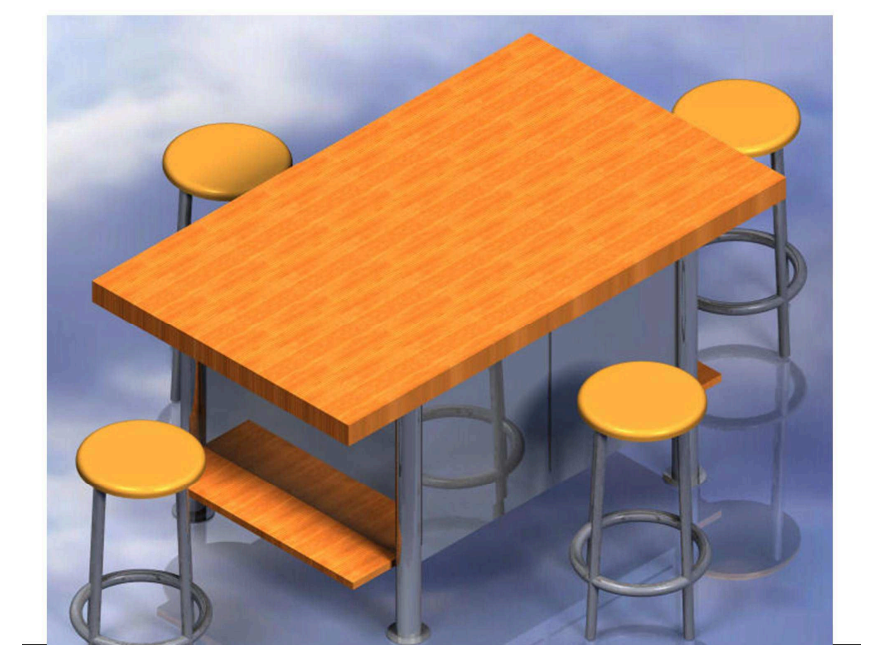

Fig. 1. Current workstation

The human models were developed based on the stature of actual subjects. Two students aged 14 year old from the same school were selected for this study. The heights of the male and female subjects were $150 \mathrm{~cm}$ and $157 \mathrm{~cm}$, respectively. Their working postures were taken during actual working condition using the current workstation. 4 most common working postures were translated into virtual environment in CATIA. Then, these working postures were evaluated using RULA assessment in the HAA tool. Figure 2 and 3 showed the male and female subjects' actual working postures in cutting and assembly task. The figures also demonstrated the human-workstation interaction in CATIA for both tasks.

The main digital items in this study were the workbench and chair. Other items were additional tools and materials to perform the tasks. These items were jigsaw machine, hammer, Medium Density Fiber board and dressed timbers. These items can be developed in CATIA. 


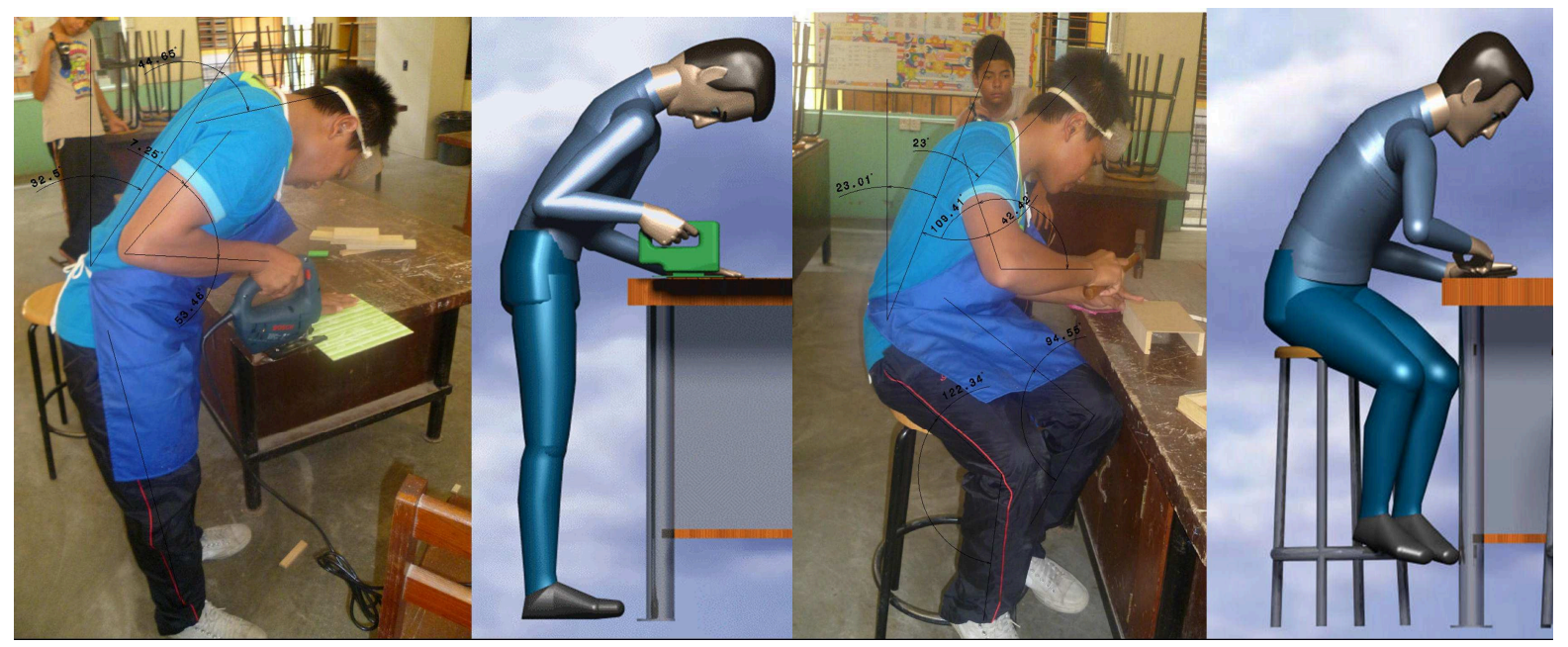

Fig. 2. Cutting and assembly tasks (Male subject)

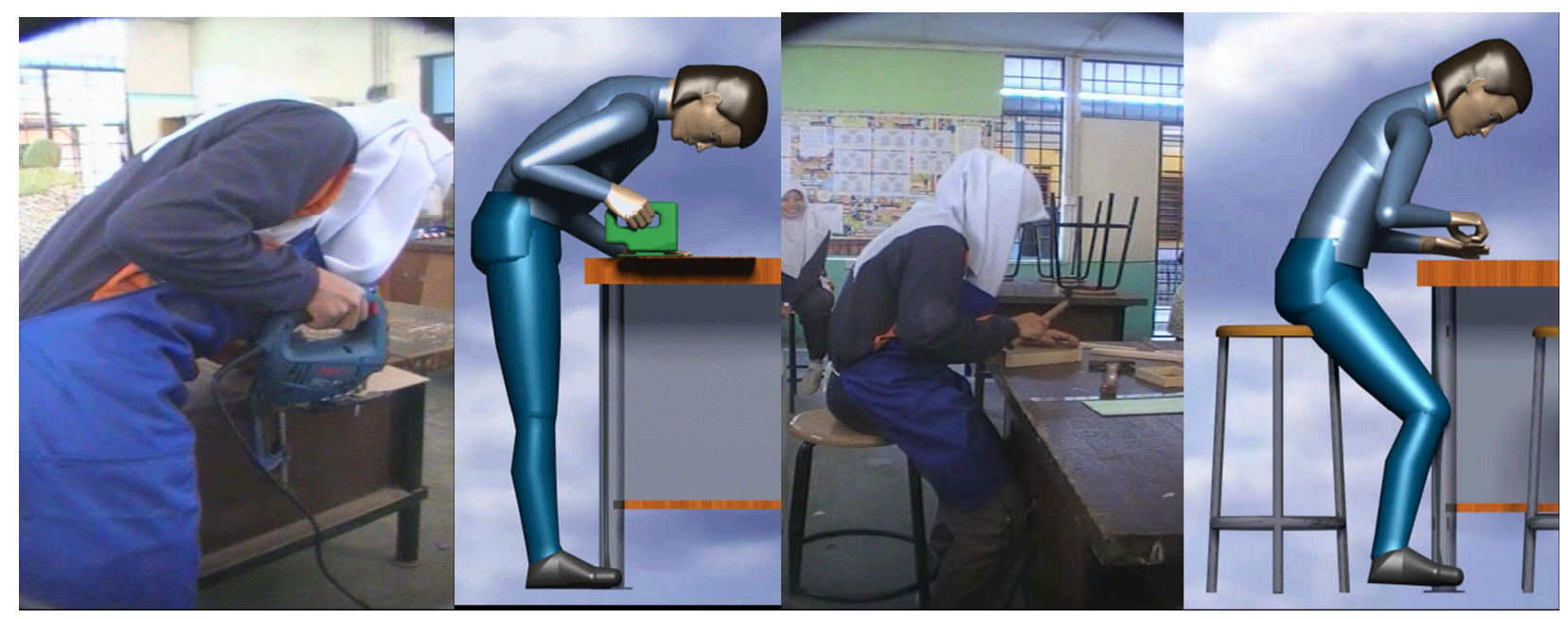

Fig. 3. Cutting and assembly tasks (Female subject)

\section{Results and discussions}

Results from RULA scores showed the current workstation is unfit for the subjects. Table 2 explained the indication of each posture. Figure 2 showed the male subject tend to adopt an awkward sitting posture. The sitting (assembly task) posture resulted in higher RULA scores compared to the female subject. On the other hand, the female subject has higher scores for standing (cutting task) posture. However, the male subject has 5.25 of average score compared to 5.00 of female subject. Nevertheless, both subjects have average scores not less than 5 which indicate their working postures are likely to develop musculoskeletal disorder (MSD) problems.

Table 2. Posture score when using current workstation.

\begin{tabular}{llccc}
\hline Gender & \multicolumn{1}{c}{ Task } & Right & Left & Indication \\
\hline \multirow{2}{*}{ Male } & Cutting & 5 & 4 & Changes are soon required. \\
\cline { 2 - 6 } & Assembly & 6 & 6 & Changes are soon required. \\
\hline \multirow{2}{*}{ Female } & Cutting & 6 & 5 & Changes are soon required. \\
\cline { 2 - 6 } & Assembly & 5 & 4 & Changes are soon required. \\
\hline
\end{tabular}


In order to reduce risk factors of MSD and back pain, this paper proposes a workstation modification as an alternative to improve the RULA postural scores and minimize ergonomic risk factors. It was discovered that design flaws in the current workstation were, no leg room and the stool provided was too high. The new-design workstation would be able to overcome these problems. Additional features for users' better comfort and safety are also included such as feet rest and bench stopper. According to Openshaw \& Taylor, workstation measurement of a target population can be determined based on the anthropometry data for possible application in product design. Table 3 showed some of the design measurements and the descriptions.

Table 3. Workstation measurements based on anthropometrics [11].

\begin{tabular}{cll}
\hline Design & Measurement & \multicolumn{2}{c}{ Description } \\
\hline & Worktop height & Elbow height \\
& Workspace envelop & Forward reach \\
Workbench & Leg room & Buttock - popliteal length, popliteal \\
& height and foot depth \\
& Under table clearance & Tight clearance \\
& Feet rest & Foot depth \\
\hline \multirow{2}{*}{ Chair } & Seat height & Popliteal height \\
& Seat depth & Buttock - popliteal length \\
& Seat width & Hip breath \\
\hline
\end{tabular}

Anthropometrics collection of the target population was obtained and shown in table 4 . The data was used as guidelines to propose the new ergonomically designed workstation. As a result, the $50^{\text {th }}$ percentile measurement was used for leg room, under table clearance, foot depth and seat height. The 50th percentile was used as most closely representative for the entire population of the target group. $5^{\text {th }}$ percentile measurement of forward reach was used for workspace envelop. $5^{\text {th }}$ percentile of elbow height was added with $18 \mathrm{~cm}$ lower measurement for worktop height. The workstation was classified for the purpose of heavy manipulative task [13]. The $5^{\text {th }}$ percentile was used to ensure no extended reach and uncomfortable working condition.

Table 4. Percentile values of anthropometric dimensions of students for workstation design in school workshop

\begin{tabular}{cccccc}
\hline $\begin{array}{c}\text { Anthropometric } \\
\text { measurements in } \\
\text { cm }\end{array}$ & $\begin{array}{c}\text { Mean } \\
(\mathbf{n}=\mathbf{1 4 5})\end{array}$ & $\begin{array}{c}\text { Standard } \\
\text { deviation }\end{array}$ & $\begin{array}{c}\mathbf{5}^{\text {th }} \\
\text { percentile }\end{array}$ & $\begin{array}{c}\mathbf{5 0}^{\text {th }} \\
\text { percentile }\end{array}$ & $\begin{array}{c}\mathbf{9 5}^{\text {th }} \\
\text { percentile }\end{array}$ \\
\hline Stature & 156.83 & 7.73 & 146.03 & 155.90 & 172.57 \\
\hline Elbow height & 97.49 & 7.70 & 90.04 & 96.50 & 106.93 \\
Shoulder breath & 32.43 & 3.86 & 27.01 & 32.20 & 39.26 \\
\hline Buttock - & 42.92 & 2.80 & 38.64 & 42.35 & 47.97 \\
popliteal length & 36.43 & 2.82 & 31.84 & 36.50 & 41.17 \\
Popliteal height & 11.65 & 2.32 & 8.27 & 11.1 & 15.97 \\
Tight clearance & 30.01 & 3.44 & 25.50 & 29.55 & 36.61 \\
\hline Hip breath & 21.27 & 1.69 & 18.83 & 21.10 & 24.58 \\
\hline Foot depth & 63.52 & 5.66 & 57.17 & 62.70 & 73.66 \\
\hline Forward reach & & & & \\
\hline
\end{tabular}

These measurements would be able to match with appropriate working height for cutting and assembly tasks and also fit the normal working envelop. All corners were made rounded edges for safety purposes. There are four square holes on the worktop for nails temporary storages.

In this study, any error in the posture parameters between all the digital humans was assumed negligible. The male human model may have the exact same posture as the female human model. 
Table 5 showed the improved RULA scores after the workstation design intervention. The average scores for both male and female subjects were 3.25. The table indicated that the new workstation design have improved subjects' working postures significantly. Even though the subjects' working conditions were still the same but they were able to work without bending too much when sitting. They also do not twist their body to fit to the workstation because there was sufficient space for the legs. Figure 4 shows the proposed workstation and human models interaction in assembly and cutting tasks.

Table 5. Posture score when using proposed workstation

\begin{tabular}{lllcl}
\hline Gender & \multicolumn{1}{c}{ Task } & Right & Left & \multicolumn{1}{c}{ Indication } \\
\hline \multirow{2}{*}{ Male } & Cutting & 4 & 3 & Changes can be required. \\
\cline { 2 - 6 } & Assembly & 3 & 3 & Changes can be required. \\
\hline \multirow{2}{*}{ Female } & Cutting & 4 & 3 & Changes can be required. \\
\cline { 2 - 6 } & Assembly & 3 & 3 & Changes can be required. \\
\hline
\end{tabular}

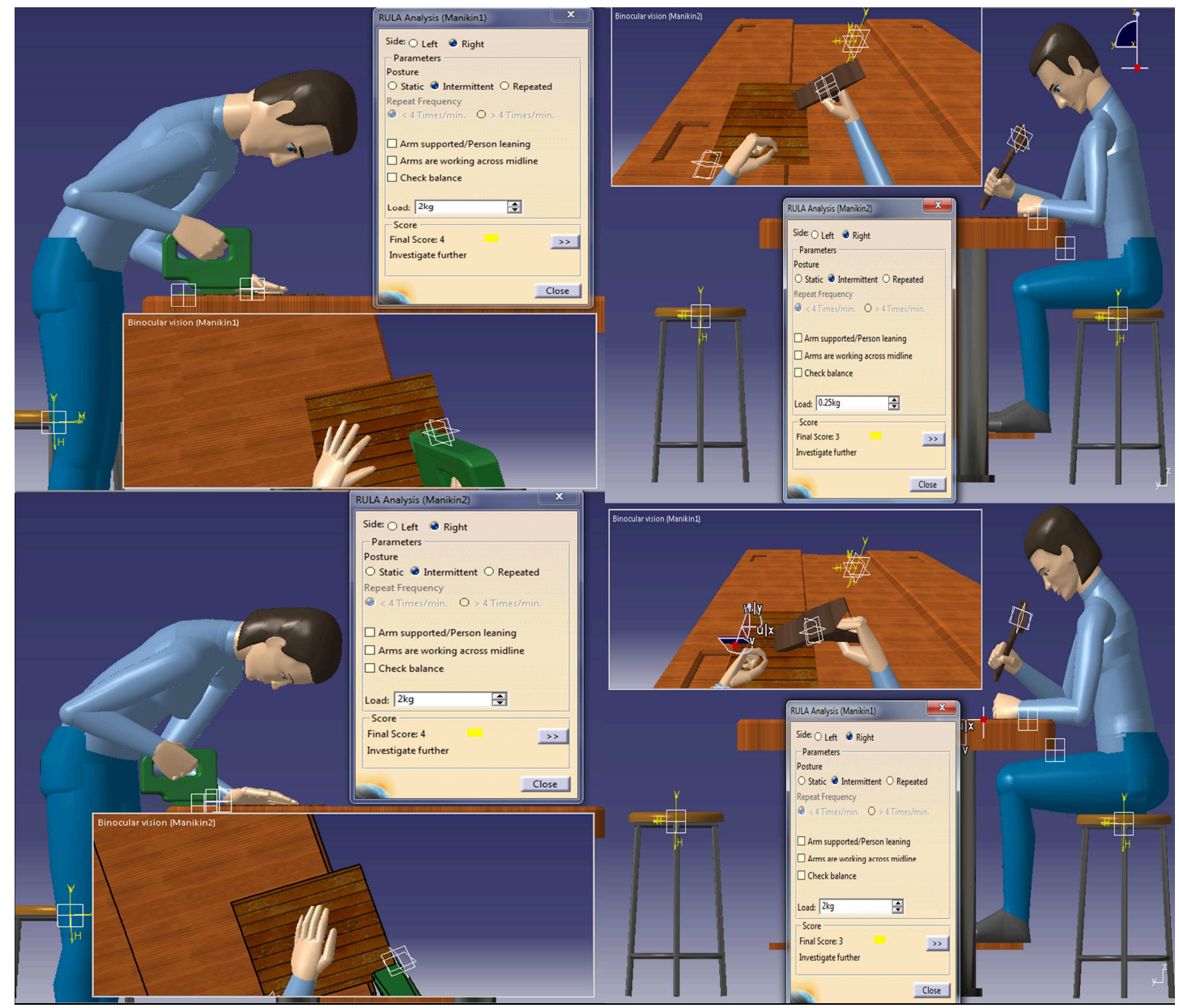

Fig. 4. Cutting and assembly tasks using proposed workstation.

\section{Conclusion}

This paper highlighted the extent of ergonomic risk factors related to schoolchildren. The footrest and leg room features in the proposed workstation have successfully improved subjects' posture scores. This study will help school administration to be more concerned about school furniture design and students' comfort. Moreover, this study was able to contribute in improving students' working postures and enhance their work performance in school workshop. A good working posture habit can reduce MSD risks in the future. 
According to Troup et al and Watson et al, musculoskeletal disorder and back pain problems in adult was contributed by having such symptoms during their previous history of pain [14, 15]. It is important to understand the symptoms of lower back pain in children and design early interventions to reduce chronic symptoms when they are adults. Musculoskeletal disorder and back pain problems in schoolchildren and adolescents may give great implications in future workforce.

Postural analysis tool is proven to be a powerful method to reduce ergonomic risks and identify design flaws. However, there is a limitation to this study. This is because we only used two subjects which are not enough to represent the whole population of schoolchildren in Malaysia. More subjects should be analyzed to identify hidden risk factors. The proposed workstation design dimensions also should refer to anthropometric database of children and adolescents age 13 to 15 years old in Malaysia.

As summary, ergonomic analysis in computer-based software are able to give desirable results for physical posture evaluation. Ergonomic simulation also can provide quantitative results which are understandable and easy to achieve [4]. It is agreed that ergonomically designed workstations are able to enhance users working postures and provide a comfortable working environment.

\section{References}

[1] I. Ben-Gal and H. Bukchin, The ergonomic design of workstations using virtual manufacturing and response surface methodology, IIE Transactions. 34 (2002) 375 - 391.

[2] R. Breen, S. Pyper, Y. Rusk and S. Dockrell, An investigation of children's posture and discomfort during computer use, Ergonomics. 50(10) (2007) 1582-1592.

[3] J. M. Brewer, K. G. Davis, K. K. Dunning and P. A. Succop, Does ergonomic mismatch at school impact pain in school children?, Work. 34(4) (2009) 455-464.

[4] Wen Cao, Ergonomic Assessment Of Sonography Workplace And Posture Parameters Using Digital Human Modeling, Binghamton University (2011).

[5] G. Colombo and U. Cugini, Virtual humans and prototypes to evaluate ergonomics and safety, Journal of Engineering Design. 16(2) (2005) 195-207.

[6] C. N. Khanam, M. V. Reddy, and A. Mirunalini, Opinion of Students on Seating Furniture Used in Classroom, Journal of Human Ecology. 20(1) (2006) 15-20.

[7] L. Kunwoo, CAD System for Human-Centered Design, Computer-Aided Design \& Applications. 3 (5) (2006) 615-28.

[8] B. Maslen and L. Straker, A comparison of posture and muscle activity means and variation amongst young children, older children and young adults whilst working with computers, Work. 32 (2009) 311-320.

[9] S. Milanese and K. Grimmer, School furniture and the user population: an anthropometric perspective, Ergonomics. 47(4) (2004) 416 - 426.

[10] S. Murphy, P. Buckle, and D. Stubbs, Back Pain Amongst Schoolchildren And Associated Risk Factors, International Ergonomics Association XVth Triennial Congress. Seoul, Korea, 16-20. (2003).

[11] S. Openshaw and E. Taylor, Ergonomics and Design. A Reference Guide. Muscatine, Iowa: Allsteel Inc (2006). 
[12] M. Pappas, V. Karabatsou, D. Mavrikios and G. Chryssolouris, Development of a web-based collaboration platform for manufacturing product and process design evaluation using virtual reality techniques, International Journal of Computer Integrated Manufacturing. 19(8) (2006) 805-814.

[13] S. Pheasant, Bodyspace. Anthropometry, Ergonomics and the Design of Work. London: Taylor \& Francis Group (2003).

[14] J. D. G. Troup, T. K. Forema, C. E. Baxter and D. Brown, The Perception of Back Pain and the Role of Psychophysical Tests of Lifting Capacity, Spine. 12(7) (1987) 645-657.

[15] K. D. Watson, A. C. Papageorgiou, G. T. Jones, S. Taylor, D. P. M. Symmons, A. Silman, J. and G. J. Macfarlane, Low back pain in schoolchildren: occurrence and characteristics, Pain. 97(1) (2002) 87-92. 